\title{
Sabores, sonidos y liturgias en Du côte de chez Swann
}

\section{Flavors, sounds and liturgies}

in Du côte de chez Swann

\section{Mariano Carou}

Artigo recebido em

$12 / 09 / 2016$

e aprovado em

01/11/2016.

V. $6-$ N. $12-2016$
* Profesor de Literatura Alemana Contemporánea y Teología de laUniversidad del Salvador, Argentina.

Email: marianitenc@ yahoo.com.ar.

\section{Resumen}

A lo largo de toda la Recherche..., pero especialmente en Du côté de chez Swann, Proust trastoca el tiempo histórico y pone a algunos de sus personajes en la situación de celebrar una suerte de liturgias (mediadas por elementos sensibles) que les permitan hacer presente en sus respectivas historias cotidianas vivencias afectivas que no pertenecen al presente, y que se convierten en verdaderos memoriales. Comparten muchos elementos con las liturgias religiosas tradicionales, pero son de alcance mucho más limitado e inmanente. De esta forma, dan cuenta no de un Amor ilimitado que se hace historia sino más bien de nuevas formas de un amor precario y limitado.

Palabras claves: Proust; liturgia; tiempo; Amor y amor.

\section{Abstract}

Throughout the entire Recherche ... but especially in Du côté de chez Swann, Proust disrupts historical time and puts some of his 
characters in the situation of holding a kind of liturgies (mediated by sensitive elements) that allow them to bring to life emotional experiences that don't belong to present in their everyday stories, and become true memorials. They are very alike traditional religious liturgies, but they are much more limited and immanent in scope. That's how they show not un unlimited Love that becomes historical, but rather new forms of precarious and limited love.

Keywords: Proust; liturgy; time; Love and love.

O

esde que los hebreos comenzaron a deshilvanar el tiempo en forma lineal, asestaron a Occidente un golpe en dos direcciónes: le ofrecieron la posibilidad de mirar a futuro y de proyectar sin sujetarse a la circularidad que regía hasta aquel entonces en las cosmovisiones reinantes; pero también inauguraron el tiempo de la nostalgia, es decir, del único viaje imposible, que es el del regreso. Mantenerse de pie frente a la absoluta linealidad del tiempo se volvió insoportable. Fue a partir de allí que se hicieron necesarios los ritos que trajeran del olvido los gestos de amor del pasado.

Proust, que en palabras de Barthes (1992) recurre nada más y nada menos que a una "mistagogia" (p.173), intenta también desentrañar esta dimensión del tiempo en una forma que, en algunos momentos, se vuelve casi litúrgica. $Y$ lo hace no por motivos azarosos, sino para convencerse y convencernos de que el amor que se inaugura en nuestra época tendrá la levedad del tiempo. Sus historias reflejarán más un desamor hecho nostalgia que un amor hecho historia; pero por eso mismo nos ofrecen un contrapunto formidable a la visión y a la obra de tantos otros autores sobre los que reflexionamos estos días. Curiosamente, para brindarnos su visión del amor-desamor lo hará a través de una resignificación de elementos tan inmemoriales como los de la liturgia religiosa.

Nos detendremos en la trilogía conocida como "Du côté de chez Swann" con la que se inicia la Recherche..., y veremos que 
en cada una de las tres partes que la componen las historias de amor se dan a través de alguna de las mediaciones sensibles necesarias para la liturgia: la forma material, la música sacra y el espacio sagrado. La palabra, el elemento restante, las atraviesa a las tres. Estos elementos no son accesorios sino vertebradores. En las dos primeras partes ("Combray" y "Un amour de Swann"), actualizan una materialización del amor evocada o anhelada; en la última parte ("Nom de pays: le nom"), la función es otra y el narrador parece más bien resignado a la vanidad del propósito: el pasado no vuelve, por más que se lo busque.

\section{Los elementos de la liturgia}

Decíamos que toda liturgia requiere de mediaciones sensibles. Veamos lo que ocurre si establecemos un paralelismo con Du côté de chez Swann. En "Combray" aparece el alimento (papel que en la liturgia cristiana realizan el pan y el vino); en "Un amour de Swann", la música (que en la liturgia no es mero acompañamiento sino oración); y en "Nom de pays: le nom", el espacio sagrado (el templo). Además, siempre hay un donante que se ofrece y se sacrifica por los demás, velando -voluntaria o involuntariamentepor que los suyos tengan lo necesario, pero sin gozar él mismo de ningún beneficio; donante que termina muriendo rodeado del reconocimiento póstumo de sus legatarios. Se hace necesaria también la presencia de un mediador, una suerte de sacerdote laico que acerque a sus destinatarios los frutos ese gesto de amor.

Toda liturgia es, en principio, la actualización celebrativa del amor hecho historia. Historia salvífica. En una sociedad religiosa solo en apariencia y en cuyo seno el positivismo todavía no había terminado de desplegar todo su poder tecnocrático, Proust apela 
a la liturgia para hacernos partícipes de la forma en que se vivía el amor en vísperas de la Gran Guerra. Claro que si las liturgias religiosas son universales, simbólicas, repetitivas, voluntarias y trascendentes, nuestro autor recurrirá a liturgias individuales, no simbólicas, únicas, involuntarias e inmanentes. Veamos por qué. A diferencia de las celebraciones religiosas, las liturgias de Proust no están destinadas al público masivo; son individuales, ya que solo quienes las viven (el joven Marcel y Swann) experimentan sus efectos. Tampoco se proponen una religación con un ser trascendente, es decir, se mantienen como rituales inmanentes. Al mismo tiempo, no recurren a símbolos que, por muy polisémicos que fueren, siempre tienen un asidero real; aquí estamos más bien en el orden de la arbitrariedad del signo, ligada exclusivamente a la propia historia del personaje (la magdalena en el caso del narrador, la frase musical en Swann). Además, no se repiten con la frecuencia que aseguraría su inserción en un tiempo definitivamente sagrado, sino que son únicas, esporádicas y, por eso mismo, con un alcance limitado. Por último, no hay una decisión voluntaria acerca del cuándo, el cómo o el dónde -en las liturgias religiosas, de hecho, hay hasta un calendario y un cronograma en el que los celebrantes se involucran-: los acontecimientos narrados aquí son repentinos y desbaratan el accionar de quien los experimenta. Estas arbitrariedades litúrgicas son, en definitiva, tan inconsistentes como el amor que pretenden actualizar.

Podría objetarse, entonces: ¿para qué confrontar un hecho literario que habla de amores inmanentes con un acontecimiento litúrgico que refiere al Amor trascendente, si las diferencias son tantas? Por una razón: ambos comparten una categoría básica, la de memorial. Tanto en la liturgia cristiana como en la hebrea (en la 


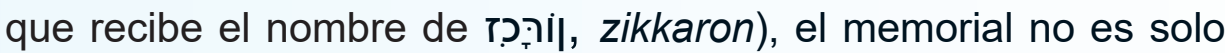
una rememoración, un recuerdo perdido, sino que por medio de una acción sensible se vuelve a hacer presente en la Historia el acontecimiento primigenio y fundante. Entre los judíos es pésaj (פon), el memorial de la acción amorosa de Dios en favor de su pueblo; entre los cristianos, la Pascua -y su repetición semanal, la misa-, memorial del sacrificio de Cristo, quien nos amó hasta el extremo $(\mathrm{Jn} 13,1)$. Esto mismo es lo que ocurre en la obra de Proust, donde la peripecia trasciende la simple evocación para ir a la médula de lo vivido. A Proust no le interesa el mero recuerdo subjetivo, individual: busca el hecho objetivo, y lo ordena en una forma desvinculada de la emoción fugaz en que los acontecimientos originales ocurrieron. Una de las claves es, precisamente, que siempre se debe a una trouvaille involontaire, en palabras de Bataille (1971, p. 3). Si fuera voluntaria, podría hacernos dudar de la intención del autor y de su objetividad. Si el autor se pone a buscar un efecto, podríamos hablar de una suerte de "profecía autocumplida", sugestión, o como quiera que se lo llame; el carácter involuntario, en cambio, nos asegura la autenticidad de la experiencia amorosa evocada.

\section{«Combray»}

En la primera parte de esta trilogía, el elemento claramente vertebrador es la comida. Esto no quiere decir (al igual que ocurrirá en los otros dos apartados) que toda la acción gire en torno a lo gastronómico, sino que las comidas cumplen un rol tan destacado que, en una novela en la que el argumento ha quedado atrás, bien podemos asirnos de ellas para intentar esbozar algunas líneas de comprensión. A los efectos de nuestro trabajo, si bien nos servire- 
mos de algunos rasgos generales del hecho alimentario en Proust, el único alimento que remite a los efectos de memorial es la famosa Madeleine, que tantos ríos de tinta ha hecho correr.

En primer lugar, veamos de qué manera el narrador comienza a exponer la situación. Nos dice que su madre le ofreció "un de ces gâteaux courts et dodus appelés Petites Madeleines qui semblaient avoir été moulées dans la valve rainurée d'une coquille de Saint-Jacques (uno de esos pastelitos llamados magdalenas, que parecen haber sido moldeados en la valva con ranuras de una conchilla de Santiago" (Proust, 2013, p. 44) ¿ ¿Hacía falta que le dijera al público francés qué son las magdalenas, populares en Francia por lo menos desde el siglo XVIII (en caso de no reconocer un origen incluso anterior)? De hecho, lo que hace Proust es también recordarnos la forma: la de la vieira, símbolo por antonomasia de los peregrinos. ¿Podemos ver aquí un guiño al lector? Algunas tradiciones sitúan el origen de estos bollos en los peregrinajes a Santiago de Compostela; de ahí la forma. Sea como sea, el narrador, peregrino del tiempo, al gustar esa Madeleine, descubre que su sabor y su aroma no eran meramente similares a los que amorosamente recibía en su infancia de parte de su tía Léonie: eran los mismos. Es decir, estamos ante un memorial:

Et tout d'un coup le souvenir m'est apparu. Ce goût c'était celui du petit morceau de madeleine que le dimanche matin à Combray..., quand j'allais lui dire bonjour dans sa chambre, ma tante Léonie m'offrait après l'avoir trempé dans son infusion de thé ou de tilleul ... Mais, quand d'un passé ancien rien ne subsiste, après la mort des êtres, après la destruction des choses, seules, plus frêles mais plus vivaces, plus immatérielles, plus persistantes, plus fidèles, l'odeur et la saveur restent encore longtemps, comme des âmes, à se rappeler, à attendre,

1.Todas las referencias a la obra de Proust están tomadas de la edición citada en la bibliografía, y las traducciones son mías. 
à espérer, sur la ruine de tout le reste, à porter sans fléchir, sur leur gouttelette presque impalpable, l'édifice immense du souvenir (p. 46). ( $Y$ de golpe el recuerdo se me apareció. Este gusto era el de un pedazo de magdalena que los domingos por la mañana, en Combray, cuando iba a saludarla a su habitación, mi tía Léonie me ofrecía luego de sumergirla en su infusión de té o tilo ... Pero cuando de un pasado antiguo nada subsiste, luego de la muerte de los seres, después de la destrucción de las cosas, solas, más frágiles pero más vivaces, más inmateriales, más persistentes, más fieles, el olor y el sabor permanecen aún mucho tiempo, como las almas, a acordarse, a esperar, sobre la ruina de todo el resto, a llevar sin flaquear, sobre su gotita casi impalpable, el edificio inmenso del recuerdo).

Otro elemento curioso es que quien provee de este alimento es una persona que, ella misma, no come más que comida de enfermo: la tía Léonie. En una dinámica de extraña sumisión, Françoise ejerce de "sacerdotisa" desde su templo, la cocina. Esta misma mujer es la que reconocerá en su jefa características de santa y mujer providente, que luego de su muerte pasó a estar en presencia de Dios ( « une bien sainte femme, où il y avait toujours de quoi, et du beau, et du bon», «une femme qui peut compter d'aller près du bon Dieu »). Alguien que, en definitiva, mostró a los demás el rostro del Amor.

\section{«Un amour de Swann »}

En la segunda parte de "Du côté de chez Swann" el elemento que nos ocupa es la música, "l'art le plus étroitement lié à la Recherche" (Gourmelon, 1971, p. 95). Si bien son muchos los autores citados con diverso propósito, es obviamente el ficticio Vinteuil quien nos interesa. El propio Proust, en correspondencia con sus amigos dejó pistas acerca de los músicos que bien podrían haberle servido de inspiración: Fauré, Franck, Saint-Saëns. A 
su vez, la famosa sonata podría remitirnos a una lista de obras, entre las cuales muchos han reconocido la sonata para violín y piano de Franck. Veamos lo que dice acerca de ella un crítico musical de la época, Camille Mauclair, quien cuatro años antes de la aparición del primer tomo de la Recherche... escribió:

Cuando oigo la Sonata para piano y violín, con su indecible preludio, tranquilo, tierno, sereno, con sus acordes como arcos blancos y ligeros, me parece oír el eco mismo del amor. Continuando el desarrollo de esas frases que mecen sinuosas, no recuerdo ya la música; esto es un lenguaje ... No sugiere nada material, no es pintoresca, ni descriptiva, no sugiere ninguna imagen: es una radiación hiperfísica y el contacto propio de lo infinito con el alma consternada, que flota, libre, finalmente (Mauclair, 1930, 172).

No es casual, entonces, la elección del autor ni del fragmento. Proust, melómano por naturaleza, escribe en medio de una revolución musical. El dodecafonismo y la atonalidad le están restando espacio a los parámetros tradicionales de la música, basados en la utilización de escalas mayores y menores derivadas de la tonalidad. Frente a las audacias de Webern o Schönberg, nuestro autor se hace eco del panorama musical francés, prefiere a los impresionistas y reivindica músicos como Franck quien, al igual que el Vinteuil de la ficción -y que la tía Léonie- fue considerado una especie de santo en vida. El rol de "sacerdote" en este caso lo ejercen los pianistas.

El mecanismo, en todo caso, es similar al de la madeleine; quien se aparece, por llamarlo así, no es un acontecimiento remoto sino la propia Odette, ella sí cargada con toda su historia de amores y desamores, de encuentros y desencuentros. La diferencia principal estriba en que se produce en Swann una suerte de anagnórisis: se reconoce a sí mismo y reconoce su situación real 
en referencia al amor que siente o sentía por Odette, amor que jamás será correspondido.

Consecuente con sus conocimientos musicales, así como decíamos que la textura y el aroma de la magdalena eran los que despertaban la evocación en el narrador, la que provoca este efecto en el caso de la sonata es la melodía, lo cual no es casual. De los tres elementos básicos de la música, la armonía se relaciona con la vida racional, el ritmo con la vida biológica y la melodía con la vida afectiva (Willems, p. 86).

\section{« Nom de pays: le nom »}

Llegamos a la última parte de la trilogía. En ella, como decíamos, se evidencian algunas diferencias con respecto a las dos primeras. Nos interesan en particular las alusiones a ChampsÉlysées, lugar en el que se producen los encuentros entre el joven narrador y Gilberte. Veamos primero qué representa el espacio sagrado en la liturgia:

\footnotetext{
El tiempo es a la duración lo que el espacio es a la extensión ... El espacio sagrado elimina la yuxtaposición y realiza más que la unidad de una simple coexistencia, hace "el uno" en Cristo, nuestra consustancialidad en Él ... Responde a la sed del Paraíso perdido; en esta superación de lo empírico operada por lo sagrado, el hombre reencuentra parcialmente su destino primero y se dirige hacia su culminación (Evdokimov, 1991, pp. 143.146).
}

En los jardines de Champs-Élysées se consuma, inocentemente, la "consustanciación" entre los dos niños, al menos en lo que respecta al anhelo por parte del narrador de unirse a Gilberte. Por la regularidad del rito, que siempre se produce a determinada hora y en circunstancias específicas, así como por la constancia del joven Marcel, estos encuentros sí se inscriben más decidida- 
mente en el horizonte de las liturgias, más aun teniendo en cuenta que los Campos Elíseos que dieron nombre a la avenida son el equivalente pagano del Paraíso cristiano.

Nuevamente es Françoise quien ejerce de facilitadora en esta rutina. Rutina que, por otra parte, ya marca un quiebre frente a la primera y segunda parte de Du côté...Si el episodio de la magdalena o el de la frase musical habían sido involuntarios, aquí hay un empecinamiento en provocar esas comuniones pasajeras que, decididamente, no se producirán. No solo porque el interés de Gilberte no es comparable al del narrador, sino también porque al abandonar su carácter involuntario se inscribe en el orden de las liturgias que están destinadas a fracasar, por darse en el tiempo real, lineal, no manipulable. Así lo percibe el joven Marcel, y así cierra esta primera parte de la Recherche:

La réalité que j'avais connue n'existait plus. II suffisait que Mme Swann n'arrivât pas toute pareille au même moment, pour que l'Avenue fût autre. Les lieux que nous avons connus n'appartiennent pas qu'au monde de l'espace où nous les situons pour plus de facilité. Ils n'étaient qu'une mince tranche au milieu d'impressions contiguës qui formaient notre vie d'alors ; le souvenir d'une certaine image n'est que le regret d'un certain instant ; et les maisons, les routes, les avenues, sont fugitives, hélas, comme les années (p. 342) (La realidad que yo había conocido no existía más. Bastaba que Mme. Swann no llegara a la hora de siempre, para que la avenida fuera otra. Los lugares que hemos conocido no pertenecen más que al mundo del espacio en el que los situamos para mayor facilidad. No eran más que una franja delgada en medio de impresiones contiguas que formaban nuestra vida de entonces; el recuerdo de una cierta imagen no es más que la añoranza de cierto instante; y las casas, las rutas, las avenidas, son fugitivas, lamentablemente, como los años).

El desencanto ya ha ganado el corazón del narrador. No hay remedio contra el tiempo; su carácter precario y fugitivo hace que 
no lo podamos manejar, y que nuestras historias de amor sean permeables a su erosión.

\section{Conclusión}

Uno vuelve invariable, inexorablemente, a los sitios donde amó la vida, como dice el poeta ${ }^{2}$. Sin ánimo de confundir autor con narrador, y más allá de lo autobiográfico que pueda ser la Recherche..., Proust ha debido amar mucho la vida para ser capaz de concebir una obra que hace de la evocación su más entrañable sustento.

A lo largo de estas líneas hemos creído adivinar una cierta relación entre las liturgias literarias de Proust y la liturgia religiosa, particularmente cristiana -a pesar del carácter inmanente que ya mencionamos-, inscribiendo este esfuerzo del autor en una sociedad que va abandonando a pasos agigantados su sustento religioso. A medida que nos acercamos a las grandes tragedias del siglo $X X$, el Amor va abandonando sus mayúsculas y se inscribe en la dinámica de lo provisorio. Frente a la caída de los grandes relatos que se hará patente al promediar el siglo XX. Proust propone una alternativa que fue posteriormente comprendida por Bataille (2008):

Si el mundo no cristiano define algún día las formas de su vida espiritual (en el sentido religioso del término), en otras palabras, si la humanidad que ya no tiene la ayuda del cristianismo llegara a realizarse, reconociera su rostro y ya no se extraviara en una multiplicidad de formas ligadas a representaciones mal definidas, falaces, fundadas en un deseo de ceguera -en el miedo-, ese rostro espiritual, cuyos rasgos se fijarían, podría parecerse al de Proust (p. 79).

Efectivamente, creemos que Proust explora y añade nuevas

2.Armando Tejada Gómez, "Las simples cosas" 
formas de encontrar sentido desde su horizonte, de brujular la noche del tiempo inmanente y hacerla menos aterradora. El desamor y el desencuentro están entre nosotros, parece decirnos, pero si al menos el sabor de una magdalena o el fraseo de una melodía persisten, estamos habilitados a creer que el Amor no está condenado a la nada y al olvido.

\section{Referencias bibliográficas}

BARTHES, Roland. El grado cero de la escritura, Buenos Aires: Siglo XXI, 1992.

BATAILLE, Georges. “Marcel Proust”, en: "L’arc”, Paris, 1971, núm. 47, 1971.

BATAILLE, Georges. La felicidad, el erotismo y la literatura, Buenos Aires: Adriana Hidalgo Editora, 2008.

BLANCHOT, Maurice. "La experiencia de Proust ", en: AAVV (1970). Proust, Buenos Aires: Editorial Jorge Álvarez, 1970.

DELEUZE, Gilles. "Les signes de l'art et de l'essence », en : AAVV. Les critiques de notre temps et Proust, Paris : Garnier, 1971.

EVDOKIMOV, Paul. Teología de la belleza, Madrid: Publicaciones Claretianas, 1991.

GOURMELON, Michelle. "L’amateur de musique », en : "L’arc", Paris, núm. 47, 1971.

LATHAM, Alison. Diccionario enciclopédico de la música, México DF: Fondo de Cultura Económica, 2008.

MAUCLAIR, Camilo. La religión de la música, Buenos Aires: Biblioteca Las Grandes Obras, 1930.

PROUST, Marcel. A la recherche du temps perdu, Paris, Gallimard : 2013.

RICHARD, Jean-Pierre. "Proust et l'objet alimentaire ", en: Littérature, $N^{\circ} 6$. Littérature. Mai 1972. pp. 3-19, 1972.

WILLEMS, Edgar. El oído musical, Barcelona: Paidós, 2001. 